\title{
VISIÓN HISTÓRICA DEL CONCEPTO DE VEJEZ DESDE LA EDAD MEDIA
}

\author{
Mari Paz Martínez Ortega* \\ María Luz Polo Luque** \\ Beatriz Carrasco Fernández***
}

\author{
* Profesora Asociada de Enfermería Geriátrica. U. de Alcalá. \\ **Profesora Titular Interina de Enfermería Geriátrica. U. de Alcalá. \\ **** Profesora Titular Interina de Enfermería Comunitaria. U. de Alcalá.
}

Dirección contacto: Departamento de Enfermería y Fisioterapia. U. de Alcalá. Campus Universitario.

Carretera de Barcelona. Alcalá de Henares. Madrid

\section{HISTORICAL VIEW OF THE CONCEPT OF AGEING FROM THE MIDDLE AGES.}

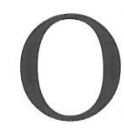
ld age is just one more stage for humans, that has been interpreted in different ways depending on the social context from which it was analysed. When it comes to consider ageing in the 21 st century, a review through space and time is needed, in order to understand this complex phenomenon in human life as a cultural -not only biological- fact.

\section{RESUMEN}

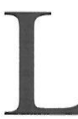

a vejez es una etapa más del ser humano que ha sido interpretada de forma variable dependiendo del contexto social en el cual se analizara. A la hora de considerar la vejez en la sociedad del siglo XXI se impone una reflexión sobre la misma a través del espacio y del tiempo, con el fin de entender este complejo fenómeno en la vida del ser humano en su totalidad, como un hecho ligado a la cultura y no solo biológico.

\section{INTRODUCCIÓN}

La consideración de la vejez ha variado en las distintas culturas y a través del tiempo. Como última etapa de la vida, próxima a la muerte, ha susci- tado interés en diferentes etapas de la historia del ser humano: Pero es ahora, dada la importancia del fenómeno del envejecimiento de la población, cuando está generando mayor expectación en la sociedad. Hoy en día es normal llegar a la vejez, mientras que en otros tiempos esto era accesible solo a una minoría. Es, pues, un fenómeno relativamente nuevo en la historia de la humanidad.

Por otra parte, el anhelo a una larga vida no es exclusivo de una época o de una cultura, es una ambición humana intemporal, representando la vejez el declive y la brevedad del ser humano. Es inevitable que inquiete y fuerce a la reflexión. La vejez es un fenómeno tan complejo, que puede ser analizado desde diferentes perspectivas, y según factores muy diversos, cronológicos, biológicos, económicos, sociales, culturales, psicológicos, antropológicos.

Por ello pensamos que, para interpretar la situación de la población anciana actual, es necesario conocer las actitudes de diferentes sociedades respecto a los viejos y las imágenes que de ellos se han forjado.

En este segundo trabajo sobre la visión histórica de la vejez, se abandona el mundo antiguo, adentrándonos en un Occidente en descomposición. A través de los años oscuros de la Edad Media, el nacimiento de la burguesía, el Renacimiento, la Ilustración, el liberalismo y los movimientos sociales de la Edad Contemporánea, 
analizaremos la evolución del concepto de vejez, así como las diferentes respuestas de la Sociedad, con el fin de comprender en profundidad las coordenadas de este fenómeno en la actualidad. Voluntariamente hemos centrado el análisis en el Occidente cristiano, dado que somos sus herederos históricos, dejando aparte, por razones operativas, la evolución del concepto de vejez en sociedades tan importantes como las islámicas o las de las diferentes culturas asiáticas.

\section{EDAD MEDIA}

La desintegración del antiguo Imperio Romano está marcada por dos acontecimientos, la escisión que da origen al Imperio Bizantino en su zona Oriental y las invasiones de las tribus germanas que estaban presionando sus fronteras occidentales. Tras la caída del Imperio de Occidente, la Iglesia que a partir de ahora se irá consolidando como una institución poderosa, conservará y trasmitirá su herencia. Se inicia aquí una larga etapa de la historia que se conoce como Edad Media y que termina con el siglo XV.

En sus comienzos "época oscura", donde la fuerza física es imprescindible para la guerra, la vida del anciano que ya no puede luchar no vale nada. Se es joven mientras la fuerza física está conservada y viejo desde que comienza su debilidad. Desde un punto de vista cuantitativo, la edad de inicio de la vejez para el hombre del Medioevo es una noción relativa, situada alrededor de los cincuenta años, sucediendo directamente a la juventud, sin lugar para la mediana edad.

Debido a las duras condiciones de la vida, el aspecto físico se deteriora prematuramente y los ancianos no son numerosos, si consideramos como en la actualidad que la vejez se inicia alrededor de los sesenta y cinco años. Es en la Iglesia donde son más numerosos pues, a salvo de las guerras, de los asesinatos políticos y gozando de una mejor alimentación, son muchos los monjes y obispos que pudieron alcanzar una edad muy avanzada.

El cristianismo no sentirá especial interés por los viejos. Para los escritores cristianos, la vejez es un problema abstracto, simbólico. Solo les interesa la fealdad de los viejos porque les proporciona una buena imagen del pecado. La vejez es claramente un mal, un castigo divino, y por el contrario, el Paraíso es el lugar de la eterna juventud. Un viejo que gozase de buena salud solo podía explicarse por una intervención diabólica o por un favor divino en un ser virtuoso. Esta visión pesimista de la vejez está heredada de escritos del Antiguo Testamento y de la tradición grecorromana. Las reglas monásticas, pilar esencial de la Iglesia, prestan poca atención a sus monjes ancianos. La más célebre, la de San Benito, los sitúa en la categoría de niños y recomienda mostrar ciertas indulgencias con ellos, pero la edad no proporciona privilegios ni es criterio para la elección de abades.

Esta falta de interés se traslada también al mundo del arte. Así, por ejemplo, este fenómeno se refleja claramente en la estilización intemporal de la escultura románica, donde la barba y los cabellos largos son los únicos atributos del viejo. Las estatuas yacentes no tienen edad.

En este contexto, los viejos pasan a depender de la voluntad de su familia, donde las prácticas varían según las circunstancias, o pasan a integrar el nutrido grupo de indigentes de la Edad Media. No obstante, a partir del siglo VI, una minoría de ancianos ricos buscaron en los monasterios un retiro tranquilo que les garantizase la salvación eterna. Esta práctica, que se extenderá en los siglos posteriores con la proliferación de los grandes monasterios que cuentan con alojamientos para ancianos, marca un hito en la historia de la vejez, pues ésta se identifica con el cese de la actividad y la ruptura con el mundo. Es el primer esbozo del asilo de ancianos, refugio y gheto a su vez. Este retiro, ahora de modo voluntario, inicia la concepción moderna del aislamiento de los viejos.

Los pobres no tenían posibilidad de retiro voluntario y trabajaban hasta que sus fuerzas se 10 permitían. Abandonados en muchos casos, su número es lo bastante importante como para justificar la fundación de varios tipos de establecimientos destinados a su socorro: enfermerías en los monasterios y hospitales, como el Hospital de San Juan de Dios, fundado en el siglo XIII. Así mismo, algunos señores mantenían a sus viejos trabajadores agrícolas.

A partir del siglo XI, la situación de los ancianos empieza a cambiar, en parte como consecuencia de las mejoras económicas y en parte debido al 
crecimiento paulatino de la burguesía. El desarrollo urbano ofreció nuevas posibilidades a los ancianos por medio del auge del comercio y los negocios. La vejez supone para el comerciante su periodo de mayor apogeo, pues el paso del tiempo le permite la acumulación de riquezas y éxitos. Pasa, pues, a formar parte de los notables de las ciudades con gran influencia en los asuntos públicos, desempeñando un papel nada desdeñable, pues fueron numerosos en la jerarquía civil y de forma especial en la eclesiástica.

También las mortíferas epidemias del siglo $\mathrm{XIV}$, en las que perecieron especialmente niños y jóvenes, produjeron un desequilibrio demográfico a favor de los viejos. La proporción de personas ancianas aumentó bruscamente a partir de 1350 , y consecuentemente trajo cambios en la mentalidad y en la estructura de la sociedad. La desintegración parcial de la familia producida por los estragos de la peste, provocó un reagrupamiento de los supervivientes en familias amplias, incluso en comunidades, que permitían asegurar la supervivencia de los más desposeídos.

Se producen entonces fenómenos curiosos, modificándose, al menos parcialmente, la visión de la vejez. Así, por ejemplo, los ancianos pasan paulatinamente a jugar un papel de vínculo entre generaciones, bien testificando en los procesos de canonización, bien escribiendo crónicas, contando historias o transmitiendo saber. A falta de pruebas escritas, es a ellos a quienes se consultaba. La edad, en opinión de la Iglesia, otorga a los viejos gran autoridad moral en materia religiosa, por lo que consideran útil su colaboración como ejemplo en la formación religiosa de las generaciones más jóvenes.

Otro rasgo característico de fines de la Edad Media fue la abundancia de casamientos en segundas nupcias entre hombres ancianos y mujeres jóvenes. La altísima mortalidad femenina que, a causa de la maternidad, seguía produciéndose, agravada por los efectos de las epidemias, fue responsable de la escasez de mujeres casaderas, lo que dio lugar a rivalidades entre jóvenes y viejos varones, siendo estos últimos, más ricos, los preferidos por las familias de las jóvenes.

La permanencia de los ancianos durante más tiempo al frente de los negocios les permitió mono- polizar más que antes los poderes de decisión, lo que acarreó en algunas ciudades un renacimiento de los conflictos generacionales que se habían atenuado tras la desaparición del Imperio Romano.

En estas fases más tardías de la Edad Media, la pintura y la escultura evolucionan hacia el realismo. Los ancianos representados dejan de ser ejemplo de los estereotipos de la vejez $y$, aunque no fueron los únicos en ser retratados, sirvieron para destacar la originalidad de los artistas. En el siglo XV apareció el verdadero retrato gracias al mecenazgo, donde se ofrece una imagen respetuosa del anciano rico e influyente que ha conseguido el reconocimiento del lugar que ocupa en la sociedad.

En este contexto socio-económico y cultural, la atención a los ancianos mejora ligeramente. La idea del retiro se extiende. Comerciantes y artesanos se organizan en algunas ciudades a través de las organizaciones gremiales, y algunas órdenes de caballería crean casas de retiro para los viejos caballeros. Por otra parte, si bien la mayor parte de los eclesiásticos cumplieron sus funciones hasta el final de su vida, algunos se vieron obligados a retirarse a causa de su decrepitud surgiendo, a partir del siglo XIII, hospicios de sacerdotes ancianos, pues la dignidad del estado eclesiástico no permitía que fuesen reducidos a la mendicidad. El número de instituciones religiosas que atienden a indigentes, en muchos casos viejos, fue en aumento.

No obstante, a fines de la Edad Media se mantiene la imagen negativa de la vejez, y tanto la novela como la poesía se prestan a desprestigiarla. Esto es especialmente importante para las mujeres. La mujer anciana, sola y pobre, se encuentra en el punto más bajo de la escala social y su equiparación con las fuerzas del mal es un rasgo característico del arte religioso de los siglos XIV y XV. La importancia social de los viejos en los siglos XIV y XV fue pasajera, pues la recuperación demográfica de fines del siglo XV hizo surgir la oleada de juventud numerosa y reivindicativa que los arrollará y se burlará de nuevo.

\section{EDAD MODERNA}

Con el Renacimiento europeo, los valores que conlleva la juventud son exaltados nuevamente, por lo que la vejez presagio de decadencia y muer- 
te fue atacada con una violencia sin precedentes. Los hombres del Renacimiento intentaron nuevamente prolongar la juventud y a través de la medicina, la magia, la alquimia, la religión y la filosofía se aunaron esfuerzos para resolver el enigma de la vejez y ponerla fin. El abundante número de obras sobre el origen y tratamiento de la vejez solo ha sido sobrepasado en la actualidad.

Los representantes del Humanismo manifestaron una opinión siempre negativa de la vejez, perviviendo la valoración social impuesta a lo largo de la Edad Media en la sociedad occidental, a pesar de que la sabiduría y la erudición cualidades que priman en el ambiente de los humanistas, son tradicionalmente aplicadas a los ancianos. Erasmo, inspirado en autores griegos y romanos, hace una cita despiadada de la vejez en su conocida obra El elogio de la locura, en la que el anciano ocupa un papel estelar.

La mujer, símbolo de la belleza, al envejecer se convertía en el símbolo máximo de la fealdad, y en la vida real este prejuicio desfavorable hace que con frecuencia se las tome por brujas. Esto se refleja tanto en la pintura, especialmente de artistas flamencos y alemanes, como en la literatura. En obras de teatro y novela picaresca de los importantes escritores españoles del Siglo de Oro, hay numerosos ejemplos de personajes, viejas llenas de vicios cuyo aspecto físico es descrito de modo exagerado y cruel. Las sátiras de Quevedo son particularmente violentas.

En la literatura erudita renacentista es excepcional la opinión favorable sobre la vejez de Luis Vives, en su Introducción a la sabiduría. Así mismo, Tomás Moro, en su obra más célebre La utopía, nos muestra el rechazo social de su época defendiendo a su vez una actitud "utópica" que sitúa a los ancianos en un digno nivel de aceptación social.

\section{Las teorías políticas del siglo XVI} (Maquiavelo, F. Bacon) muestran en sus discursos mayor confianza en la juventud, respondiendo a un sentimiento generalizado de la sociedad aunque no a la realidad existente. No obstante, hay una evidente contradicción entre la imagen teórica que se da a la vejez y el papel desempeñado por muchos ancianos en la sociedad al frente de cargos de gran responsabilidad en la política, la economía y el arte tanto en ambientes laicos como eclesiásticos.
Esta contradicción también se aprecia en los ambientes artísticos. Shakespeare, magnífico observador, supo expresar la situación ambigua de la vejez, no solo de su época sino en una dimensión universal. Pintores como Durero, Rafael o Tiziano dulcificaron rasgos y actitudes en sus retratos de ancianos, para que sin perder el realismo se les mostrara con una imagen más amable. Incluso a nivel popular existe una visión contrapuesta del problema, como puede observarse en el refranero popular ("Del viejo el consejo". "El niño viene, el mozo está, el viejo se va").

Al llegar al siglo XVII las críticas en la literatura bajan de tono y se concede al viejo mayor valor que en siglos precedentes. Corneille creó figuras de ancianos que siguen siendo hombres a los que ningún sentimiento humano les está vedado por la edad. Entre la burguesía en auge, enriquecida por el comercio, se reconoció la autoridad de las personas de edad más avanzada en las que se respetaba al hombre rico y no al de edad como tal, aunque a partir de los 50 años de edad era difícil mantener su puesto en la sociedad.

En todo este periodo, las actitudes generales de atención a los ancianos fueron comparables a las existentes al final de la Edad Media. En las clases privilegiadas, prevalecieron la atención por la propia familia, persistiendo la tendencia al retiro monástico. Entre campesinos y artesanos siguió siendo fundamental el sistema de mantenimiento familiar. La Iglesia socorría a necesitados en los asilos y hospitales fundados, pero estos auxilios eran muy insuficientes.

Desde finales del siglo XVIII hasta mediados del siglo XIX se iniciaron en Europa una serie de cambios que produjeron una profunda transformación en la sociedad. La población inicia y mantiene un ritmo de crecimiento regular y continuado, que caracteriza ya a la época contemporánea, y que supuso un aumento y rejuvenecimiento de la misma. A esta transformación demográfica van unidos cambios sociales, económicos y políticos.

La clase dominante, formada por la aristocracia y el clero, que basaban su poder absoluto en la propiedad de la tierra, fue siendo desplazada por la burguesía que adquiere de forma creciente el poder económico y social. Se produjo el paso de una sociedad de estructura agrícola y mercantil a otra 
de carácter industrial y financiero y esta primera revolución industrial constituyó el inicio del proceso capitalista. Junto a estos cambios se produjo una revolución intelectual (Siglo de las Luces) en el que se apoyó ideológicamente el Despotismo Ilustrado que influyó en todo el pensamiento europeo. La asistencia pública fue reformada estimulando la Beneficencia, y se atenuó la miseria de algunos ancianos.

A pesar de todos estos cambios, el ideario respecto al papel del anciano no se modificó en general. En las clases privilegiadas, los ancianos se beneficiaron del suavizamiento de las costumbres, donde una vida social más compleja exigía cualidades de experiencia, de inteligencia y menos esfuerzo físico. El tiempo de la vida activa se alargó y los sexagenarios intervenían en la vida social.

Las empresas eran familiares y el jefe el miembro de mayor edad. La burguesía en ascenso creó una ideología que valorizó la vejez, porque el anciano simboliza la unidad y la permanencia de la familia, permitiendo a través de ella la transmisión de las riquezas y su acumulación, que es la base del capitalismo y el individualismo burgués. El jefe de familia envejecido gozó de prestigio conservando sus propiedades.

Estos cambios se manifestaron claramente en la literatura de la época. En el teatro del siglo XVIII se inició una evolución de la figura del viejo, desempeñando papeles donde se les muestra majestuosos y conmovedores. También los viejos pobres ingresan tímidamente de la mano del "viejo servidor abnegado", aunque su figura solo interesa en relación a su amo.

\section{EDAD CONTEMPORÁNEA}

El extraordinario empuje demográfico iniciado a fines del siglo XVIII se acompaña durante el siglo XIX de tres fenómenos de gran relevancia que transformaron la sociedad europea, la revolución industrial, el éxodo rural que acarreó el surgimiento urbano y la aparición y desarrollo de una clase nueva (el proletariado). Al finalizar el siglo, la industria ofrece trabajo a los hijos de los campesinos que no pueden competir con los propietarios ricos que van introduciendo los progresos técnicos en la explotación de las tierras.
Estas transformaciones fueron nefastas para los viejos, pues al avanzar en edad los obreros no podían soportar el ritmo de trabajo, por lo que morían prematuramente o cuando sus escasas fuerzas les privaba del empleo quedaban reducidos a la miseria, pues carecían de cobertura económica por parte de la empresa o el Estado.

A mediados del siglo XIX terminó de completarse la revolución industrial y en este mundo en movimiento, donde la figura más considerada es la del empresario, la iniciativa era la cualidad más necesaria y los hombres jóvenes se imponían por su audacia. Las sociedades anónimas por acciones sustituyen al capitalismo familiar y el hombre de edad perdió prestigio y poder, pero se estableció una especie de equilibrio entre generaciones pues era tan necesaria la experiencia que aportaban los ancianos como la inventiva de los más jóvenes.

La literatura del siglo XIX, en conjunto, consideró la vejez con un criterio realista. Los novelistas se esforzaron por trazar un cuadro completo de la sociedad y describen a los ancianos pertenecientes a las clases dirigentes y las pertenecientes al resto de las capas sociales. En los obras de los novelistas rusos casi no se encuentran viejos obreros puesto que en realidad en el proletariado era difícil llegar a viejo, pero las figuras de los viejos campesinos son numerosas. Es obligado resaltar la obra de Víctor Hugo donde la vejez es tratada con amplitud y exaltada con vehemencia.

Los avances técnicos y científicos, junto con cambios sociales e ideológicos, no supusieron una inmediata mejora en las condiciones de vida de los menos favorecidos socialmente. El progresivo desarrollo de las sociedades industriales provocó un creciente desprestigio de la vejez, pero al aumentar el número de ancianos y su esperanza de vida en todas las clases sociales, gracias a los avances en el campo de la medicina, la higiene, salud pública, el anciano va alcanzando una mayor representatividad social y deja de ser un problema individual y familiar para cobrar significado público y convertirse en un problema social que tiene trascendencia a nivel político.

Así mismo los progresos de la industrialización han conducido a una disolución cada vez más acentuada de la célula familiar, que unido al considerable y progresivo envejecimiento de la pobla- 
ción han obligado a la sociedad a crear leyes, normativas y programas que aborden y den solución a los problemas que plantea la vejez de su población. Es una de las preocupaciones más urgentes de los Estados en el momento actual.

Estos cambios en las formas de vida conducen a la marginación social del anciano, y él mismo se siente con frecuencia superviviente de un mundo que le es cada día más ajeno, hasta el punto que el tiempo que el anciano considera el suyo está en el pasado ("en mis tiempos...") porque la época que vive pertenece a los jóvenes. La jubilación que la sociedad impone al hombre de cierta edad, que se encuentra en una buena situación física e intelectual le supone el apartamiento social definitivo y la perdida de su lugar en la sociedad que le margina y en la que los valores propios de la juventud devalúan los valores que el anciano puede ofrecer al grupo humano al que pertenece. La experiencia acumulada por los años no tiene gran valor en la sociedad tecnocrática actual, donde prima la competitividad y es necesaria una rápida adaptación a las nuevas tecnologías que se renuevan constantemente.

Dado el número de documentos que poseemos sobre la condición actual de los viejos y las posibilidades que los medios audiovisuales nos proporcionan sobre la realidad social, los que nos proporciona la literatura tienen un lugar secundario, y por lo general anecdótico.

El principal deseo de los ancianos ha sido y es vivir el máximo tiempo posible conservando en la comunidad los roles que dan sentido a la vida humana ("vivir mientras la vida valga más que la muerte") en relación con la cultura propia de cada sociedad. Una vida con sentido ha de tener satisfechas las necesidades básicas tanto de tipo biológico como social (pertenecía e integración en el grupo). La sociedad actual tiende a satisfacer en los ancianos las necesidades biológicas meramente materiales mientras que por otra parte los margina socialmente.

\section{CONCLUSIONES}

El rechazo de la vejez se manifiesta, como ya se ha expuesto, de modo diferente según cada sociedad y cultura pero siempre está presente.

Vivimos en una sociedad que ensalza la juven- tud y niega el proceso natural de envejecimiento invitando a disimular sus efectos sobre el aspecto físico y a realizar actividades de ocio que transmitan una imagen juvenil. En general se espera que los ancianos se comporten con dinamismo pero paralelamente en el orden moral se les imponen obligaciones, en el modo de vestir, respeto a las apariencias y una importante represión en el terreno sexual.

Se puede afirmar que el colectivo de personas mayores como grupo de edad diferenciado, con intereses propios, con rasgos culturales específicos y con exigencias sociales definidas, es el último que históricamente ha irrumpido en nuestro complejo marco social.

La sociedad ha elaborado unas pautas y modelos de vejez dinámica y consumista, difundida ampliamente a través de los poderosos medios de comunicación, que sin llegar a ser totalmente asumidos por los ancianos, a falta de otros referentes son aceptados.

Aunque muy lentamente hay una tendencia en los ancianos actuales hacia la búsqueda de respuestas a los problemas planteados por ellos mismos, intentando superar la consideración de población marginada por parte del resto de los grupos de edad, en respuesta a la falta de patrones propios y específicos para ellos, un colectivo por otra parte muy heterogéneo.

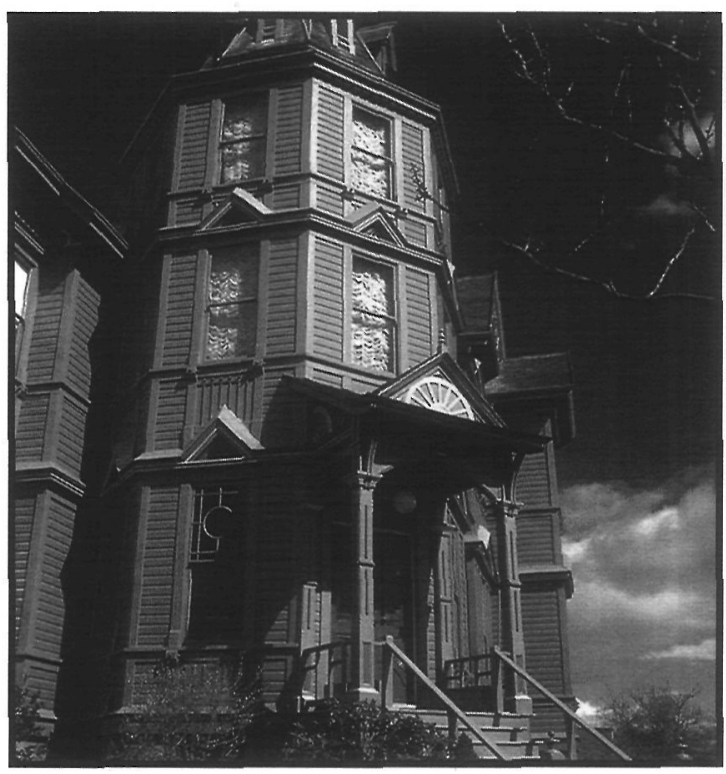




\section{BIBLIOGRAFIA}

Alba V ( 1992). Historia social de la vejez. Laertes, Barcelona (Libro)

Arquiola E (1995). La vejez a debate. Análisis histórico de la situación sociosanitaria de la vejez en la actualidad. Estudios sobre la ciencia .CSIC. Madrid (Libro)

Beauvoir, S de (1983). La vejez, Edhasa, Barcelona (Libro)

Fericqle, M (1989). Envejecer, una antropología de la ancianidad. Editorial del Hombre.(Libro)

García MV, Toronjo A, Rodriguez C (2001). Enfermería del anciano. Pg. 33-40. Difusión avances de enfermería. Madrid (Capítulo de libro)
Grangel, LS (1991). Historia de la vejez. Universidad de Salamanca. Salamanca (Libro).

Laforest J.(1991). Introducción a la Gerontología. El arte de envejecer. Herder Barcelona (Libro)

Manrique Sáez P (1999). Consideraciones sobre la vejez desde la prehistoria hasta la peste negra. Gerokomos Vol.10(4), 156-160. (Artículo de revista).

Minois, G (1989). Historia de la vejez. Nerea. Madrid.(Libro).

Struve V.V(1978), Historia de la Antigua Grecia. Akal (Libro)

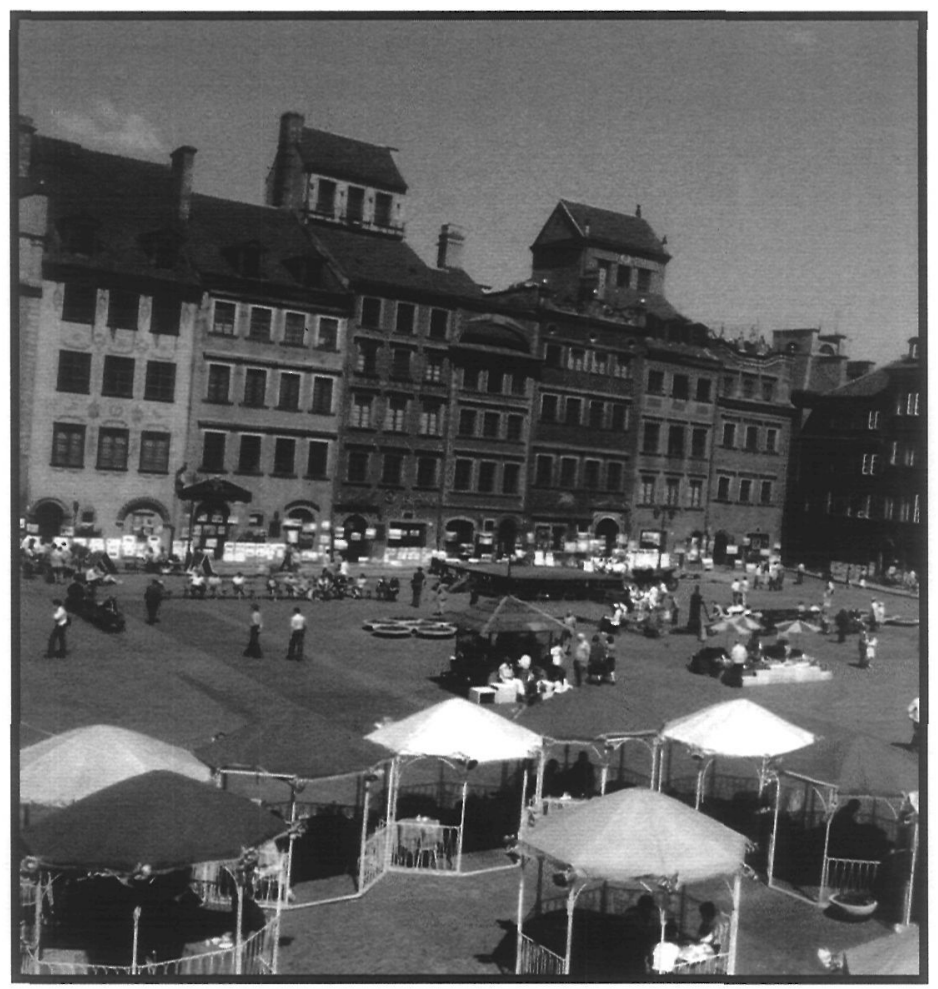

